\title{
Purification and characterization of a protein antigen from Leptospira interrogans serovar hardjo, common to a wide range of bacteria
}

\author{
Susan A. Ballard,* Solly Faine and Ben Adler \\ Department of Microbiology, Monash University, Clayton, Melbourne, Victoria 3168, Australia
}

(Received 25 January 1990; revised 2 May 1990; accepted 31 May 1990)

\begin{abstract}
A protein with a molecular mass of $64 \mathrm{kDa}$ (P64) from Leptospira interrogans serovar hardjo was partially purified by using successively, phase partitioning with Triton X-114, ion-exchange chromatography and sucrose gradient centrifugation. Purification to homogeneity was obtained by electroelution of P64 from SDS-polyacrylamide gels. Monospecific rabbit antiserum (R $\alpha \mathbf{P 6 4})$ was prepared using the purified protein preparation. P64 had a native molecular mass of $>670 \mathrm{kDa}$ and was recognized by $\mathrm{R} \alpha \mathrm{P} 64$ as well as by human antisera. Western blotting of leptospiral serovars and 18 other bacterial species with $\mathrm{R} \alpha \mathrm{P} 64$ showed that P64 was cross-reactive with an equivalent antigen in a wide range of bacteria, indicating that it belongs to a family of antigens previously designated 'common antigen'. This putative common antigen from Leptospira appears to have a sub-surface location, but its function is not yet known.
\end{abstract}

\section{Introduction}

Leptospirosis is an acute febrile disease caused by members of the species Leptospira interrogans. In Australia and New Zealand, infections are most frequently caused by serovars hardjo and pomona acquired mainly from cattle and pigs, respectively. Information about the nature and identity of antigens recognized by antibodies produced during naturally acquired leptospirosis is important to elucidate those antigens with significance for pathogenesis, immunity or diagnosis. Immunity to leptospirosis is humorally mediated and antibodies involved in opsonization and agglutination of leptospires are of prime importance (McGrath et al., 1984; Vinh et al., 1982). To date, lipopolysaccharide (LPS) is the only agglutinating and opsonic leptospiral antigen to be identified (Adler \& Faine, 1983; Farrelly $e t$ al., 1987; Jost et al., 1986) and recent studies indicate that immunization with LPS can confer protection from infection (Jost et al., 1989).

The significance of protein antigens however is not clear. Nunes-Edwards et al. (1985) studied the protein antigens of serovar hardjo using radioimmunoprecipitation with immune rabbit sera. They identified a number of proteins with molecular masses between 30 and $67 \mathrm{kDa}$, most of which were present in the outer envelope and apparently exposed on the leptospiral cell

Abbreviation: LPS, lipopolysaccharide. surface. However, nothing is known of the identity of these proteins nor of their roles in pathogenesis and immunity to infection. In other studies, protein antigens of 33,34 and $37 \mathrm{kDa}$, recognized by human sera, were identified as flagellar components (Kelson et al., 1988; Chapman et al., 1988). Jost et al. (1988) identified a $35 \mathrm{kDa}$ species-specific protein antigen in the outer envelope of the leptospire which is also recognized by human antisera. These antigens are neither opsonic nor do they elicit the production of agglutinating antibodies. Studies of a leptospiral genus-specific antigen, partially purified from serovar kremastos, was identified as a $62 \mathrm{kDa}$ non-agglutinating sub-surface protein (Sakamoto et al., 1985a). Whilst the significance of this protein in the leptospire is unknown it has been proposed as a useful screening antigen for the diagnosis of human leptospirosis (Sakamoto et al., 1985b).

In recent years much attention has been paid to a family of conserved bacterial proteins referred to as common antigen(s). This antigen was originally identified as an immunoreactive protein with a molecular mass of $62 \mathrm{kDa}$ in Pseudomonas aeruginosa (Hoiby, 1975; Sompolinsky et al., 1980) and Escherichia coli (Kaijser, 1975). Since those observations, common antigen has been demonstrated in more than 60 different bacteria including Gram-negative and Gram-positive bacteria, spirochaetes and archaeobacteria (Hansen et al., 1988). These proteins, which display common structural and 
immunological features, are major immunogens and antigens during infections with corresponding bacteria.

A study of the human antibody response to infection with $L$. interrogans serovar hardjo by Chapman et al. (1988) identified a $64 \mathrm{kDa}$ protein antigen (P64) recognized exclusively by IgG class antibodies. Antibodies against this protein were also produced by some humans following vaccination with a formalin-killed bivalent vaccine consisting of serovars hardjo and pomona grown in protein-free medium (A. J. Chapman, personal communication). This paper reports the purification of P64 and its characterization as the putative common antigen of Leptospira. As the mycobacterial common antigen has been identified as a heat-shock protein as well as being implicated in the pathogenesis of experimental autoimmune adjuvant arthritis (Van Eden et al., 1988), knowledge of a leptospiral common antigen may have significance in the further understanding of leptospiral pathogenicity.

\section{Methods}

Bacterial strains. Leptospira interrogans serovar hardjo strain 171 was a bovine isolate obtained from R. B. Marshall, Massey University, New Zealand. All other leptospiral strains used were provided by the WHO Leptospira Reference Laboratory, Brisbane, Australia. Leptospires were grown in Tween 80/BSA medium with added pyruvate (Johnson et al., 1973) and counted in a Petroff-Hauser bacterial counting chamber. Treponema pallidum (Nichols) sonicate was provided by D. Dickeson, Westmead Hospital, Sydney, Australia. Borrelia burgdorferi sonicate was provided by R. Munro, Liverpool Hospital, Sydney, Australia. Mycobacterium bovis BCG was provided by A. Basten, University of Sydney, Australia. Other Gram-negative and Gram-positive bacteria were obtained from the culture collection of the Department of Microbiology, Monash University, Melbourne, Australia.

Purification of P64. All purification procedures were done at $4{ }^{\circ} \mathrm{C}$ unless otherwise stated. Leptospires from 1 litre of an exponential phase culture were pelleted by centrifugation at $16300 \mathrm{~g}$, washed three

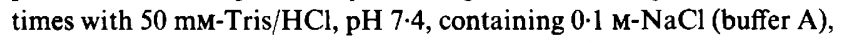
and disrupted by sonication (Adler et al., 1980). Triton X-114 was added to a final concentration of $2 \%(\mathrm{v} / \mathrm{v})$ and incubated overnight. Insoluble material was removed by centrifugation at $12100 \mathrm{~g}$ for $30 \mathrm{~min}$, the supernatant was collected and subjected to phase partitioning (Radolf et al., 1988). The aqueous phase was retained and concentrated in an Amicon stirred cell concentrator using an XM50 membrane prior to loading onto a DEAE-Sepharose CL-6B column $(1.5 \times 30 \mathrm{~cm})($ Pharmacia) equilibrated with buffer $A$. The column was washed with buffer $A$ and $2 \mathrm{ml}$ fractions collected and tested for $\mathrm{P} 64$ by SDS-PAGE and Western blotting with human serum. Fractions containing P64 were pooled and concentrated as described earlier, before loading onto a $12 \mathrm{ml} 10-40 \%(\mathrm{w} / \mathrm{v})$ sucrose/buffer A gradient and centrifuged at $284100 \mathrm{~g}$ in an SW 40 rotor for $40 \mathrm{~h}$ in a Beckman L2-65B ultracentrifuge. Sucrose fractions containing P64, determined by SDS-PAGE and Western blotting, were pooled and dialysed against buffer $\mathrm{A}$ and stored at $4{ }^{\circ} \mathrm{C}$.

Antisera and serological methods. Antiserum was produced against SDS-PAGE-separated P64 by the method of Boulard \& Lecroisey
(1987). Coomassie-blue-stained P64 was excised from the gel, macerated and emulsified with incomplete Freund's adjuvant $(1: 1.5, \mathrm{v} / \mathrm{v})$. Female New Zealand White rabbits were given one intramuscular injection of this material containing approximately $20 \mu \mathrm{g}$ protein. Rabbits were injected 3 weeks later, intradermally in 10 sites, with $20 \mu \mathrm{g}$ P64 electro-eluted from SDS-polyacrylamide gels by the method of Jacobs \& Clad (1986) and emulsified in adjuvant as before. Human sera from Australian patients reacting with P64 were selected from specimens submitted to this laboratory for leptospirosis diagnostic serology. Human anti-T. pallidum serum was provided by D. Dickeson, and rabbit anti-B. burgdorferi serum was provided by $\mathrm{R}$. Munro. The anti-serovar hardjo LPS monoclonal antibody was described previously (Farrelly et al., 1987) as were the methods for the microscopic agglutination test (Adler \& Faine, 1978). Opsonization of leptospires for phagocytosis by mouse peritoneal macrophages and visualization by indirect immunofluorescence staining were done as described previously (Farrelly et al., 1987). A fluorescein isothiocyanateconjugated sheep anti-rabbit serum (Silenus Laboratories, Melbourne, Australia) was used as the second antibody. Indirect immunofluorescence was also done on acetone-fixed leptospires and visualized using a Zeiss IM35 inverted epifluorescence microscope (Vinh et al., 1984).

Preparation of leptospiral antigens. Leptospiral outer envelope and protoplasmic cylinders were prepared from serovar hardjo as described by Auran et al. (1972). Cytoplasmic and membrane fractions were prepared as described by Ito et al. (1977). Flagella were prepared according to the method of Chang \& Faine (1970) and leptospiral sonicates were prepared as described by Adler $e t$ al. (1980). The protein content of these leptospiral antigens, P64 and other bacterial strains were determined by the method of Bradford (1976) using bovine $\gamma$ globulin (Becton Dickinson) as the standard.

$P A G E$ and Western blotting. Antigens were electrophoresed on discontinuous SDS-polyacrylamide $7 \%$ or $10 \%(\mathrm{w} / \mathrm{v})$ gels in a Protean gel apparatus (Bio-Rad) and stained for protein using Coomassie brilliant blue (Chapman et al., 1987) or silver-stained by the method of Morrissey (1981). Gels were also transblotted onto nitrocellulose $(0.45 \mu \mathrm{m}$, Scheicher and Schuell) in a Bio-Rad transblot cell and immunostained with sera followed by peroxidase-conjugated goat antirabbit immunoglobulins (Bio-Rad), sheep anti-mouse immunoglobulins (Silenus Laboratories) or sheep anti-human immunoglobulins (Silenus Laboratories) as described by Chapman et al. (1987). Bands were visualized with 4-chloro-1-naphthol as described by Hawkes $e t$ al . (1982) and their molecular masses determined by comparison with standard proteins (Pharmacia). Blotted antigens digested with proteinase $\mathrm{K}\left(100 \mu \mathrm{g} \mathrm{ml}^{-1}\right.$; Protease-type XI, Sigma) in buffer A were incubated at $37^{\circ} \mathrm{C}$ for $24 \mathrm{~h}$. Control blots were incubated in buffer $A$ only.

Native PAGE was done as for discontinuous SDS-PAGE with the exception that SDS was omitted from all reagents used. Samples were prepared in the absence of dithiothreitol and SDS without boiling and transblotting was done in the absence of methanol.

Two-dimensional electrophoresis was done as described by Milner $e t$ al. (1987) using 7\% (v/v) acrylamide slab gels in the second dimension.

Elution of antibodies from nitrocellulose following Western blotting was done as described by Beall \& Mitchell (1986) with the following modifications. Nitrocellulose strips were washed with $0 \cdot 1 \mathrm{M}$-Tris $/ \mathrm{HCl}$, pH 7.4, containing $0.5 \mathrm{M}-\mathrm{NaCl}$ (TBS) prior to elution of antibodies. Eluted antibodies were diluted $1: 2$ with $5 \%(\mathrm{w} / \mathrm{v})$ skim milk in TBS containing $0.05 \%(\mathrm{v} / \mathrm{v})$ Tween 20 and used immediately.

Enzyme activity assays. Protease activity of purified P64 was assayed using Azocoll (10 mg ml-1 ; <50 mesh, Calbiochem) as a substrate according to the assay procedure recommended by the manufacturer. Proteinase $\mathrm{K}$ ( 1 to $20 \mu \mathrm{g} \mathrm{ml}^{-1}$ ) was used as a positive control. Soluble products produced as a result of enzymic degradation of Azocoll were measured by spectrophotometry at $520 \mathrm{~nm}$. 
Haemolysis of sheep erythrocytes by serovar hardjo $\left[10^{9}\right.$ cells $\mathrm{ml}^{-1}$ in phosphate buffered saline (PBS, 0.15 M-sodium chloride, 0.15 Msodium phosphate, $\mathrm{pH} 7 \cdot 2)]$ and P64 (10 $\mu \mathrm{g} \mathrm{ml}^{-1}$ PBS) was measured photometrically at $540 \mathrm{~nm}$. Erythrocytes were washed and resuspended in PBS to a concentration of $4 \%(\mathrm{v} / \mathrm{v}) ; 0.5 \mathrm{ml}$ of washed leptospires or P64 were mixed with $0.25 \mathrm{ml}$ erythrocytes and $0.25 \mathrm{ml}$ PBS and then incubated at $37^{\circ} \mathrm{C}$ for $18 \mathrm{~h}$. The optical density of supernatants measured was converted to percentage lysis of erythrocytes by reference to a standard curve of optical densities of different dilutions of erythrocytes completely haemolysed by distilled water. Haemolysis inhibition studies were done by replacing $0.25 \mathrm{ml}$ PBS with R $\alpha \mathrm{P} 64$ or normal rabbit serum in the assay procedure.

Cytotoxicity assays on L929 fibroblasts were done as described by Vinh et al. (1986) by measuring release of lactate dehydrogenase (LDH) from damaged L cells (Mitchell et al., 1980).

\section{Results}

\section{Purification of P64}

Leptospires from a 1 litre culture were washed, sonicated and subjected to phase partitioning by Triton X-114. P64 was found exclusively in the water phase. This fraction was applied to a DEAE-Sepharose CL-6B column and eluted in a single peak using buffer A. Fractions containing P64 were pooled and concentrated prior to loading onto sucrose gradients. After centrifugation, P64 was recovered from fraction 1 and dialysed against buffer A; approximately $500 \mu \mathrm{g}$ of protein was obtained from $10^{12}$ leptospires. The purification procedure was monitored by SDS-PAGE and Western blotting with human serum and an anti-LPS monoclonal antibody. P64 appeared as a single band when stained by Coomassie brilliant blue and Western blotting with human serum; in addition, contaminating LPS could not be detected in this preparation when immunostained using an anti-LPS monoclonal antibody (Fig. 1). However, protein silver staining of P64 in SDS-PAGE gels revealed the presence of contaminating material. Subsequently P64 was further purified by SDS-PAGE and electro-elution and was designated pP64; pP64 appeared as a single band of protein by gel electrophoresis when silver-stained. The protein nature of P64 was confirmed when Western blots were treated with proteinase $\mathrm{K}$ and stained with human serum. Proteinase $\mathrm{K}$ treatment completely abolished the reaction of human serum with P64 whereas the control blot was unaffected (not illustrated).

\section{Production and characterization of antiserum to pP64}

Rabbit antiserum was produced by immunization with pP64 and tested for reactivity by Western blotting of serovar hardjo sonicate and P64, electrophoretically resolved on $7 \%(\mathrm{w} / \mathrm{v})$ SDS-polyacrylamide gels. Rabbit
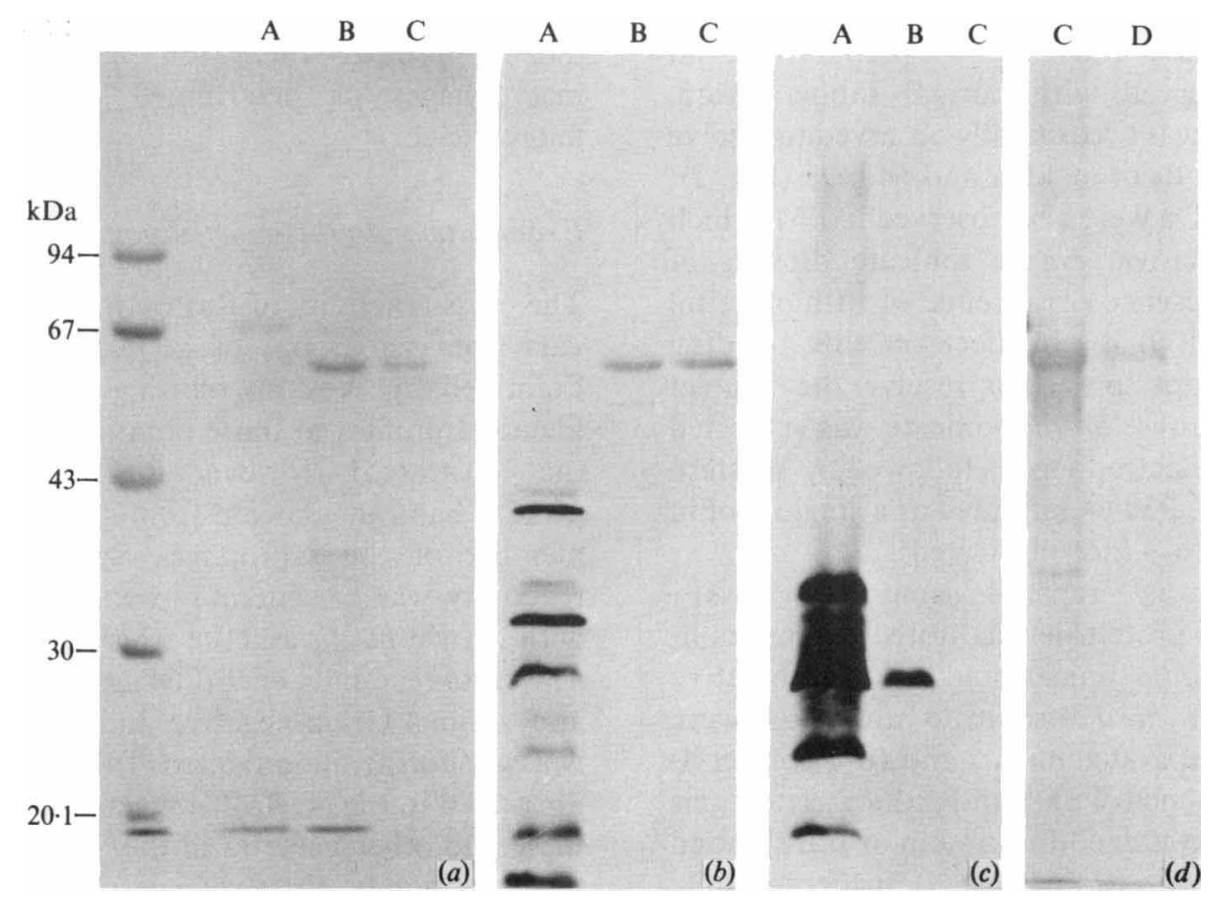

Fig. 1. Evaluation of the P64 purification procedure by SDS-PAGE. Gels were either stained with Coomassie blue (a), silver-stained for protein $(d)$, or immunoblotted with human antiserum $(b)$ or an anti-LPS monoclonal antibody $(c)$. Lanes : A, serovar hardjo sonicate; B, pooled ion-exchange fractions containing P64; C, sucrose gradient fraction containing P64; D, P64 after electroelution from SDSpolyacrylamide gels. The left-hand lane in $(a)$ contains standard proteins. 
Table 1. Cross-reactivity of $R \alpha P 64$ with leptospiral sonicates

$\mathrm{R} \alpha \mathrm{P} 64$ cross-reacted with sonicates of each of the serovars listed.

\begin{tabular}{lll}
\hline \hline \multirow{2}{*}{ Species } & \multicolumn{1}{c}{ Serogroup } & \multicolumn{1}{c}{ Serovar } \\
\hline L. interrogans & Australis & australis \\
& Autumnalis & autumnalis \\
& Ballum & ballum \\
& Bataviae & bataviae \\
& Canicola & canicola \\
& Celledoni & celledoni \\
& Cynopteri & cynopteri \\
& Djasiman & djasiman \\
& Grippotyphosa & grippotyphosa \\
& Hebdomadis & hebdomadis \\
& Icterohaemorrhagiae & copenhageni \\
& Javanica & javanica \\
& Mini & mini \\
& Panama & panama \\
& Pomona & pomona \\
& Pyrogenes & zanoni \\
& Sarmin & sarmin \\
& Shermani & shermani \\
& Tarassovi & tarassovi \\
& Semaranga & patoc \\
\hline \hline & & \\
& & \\
& &
\end{tabular}

antiserum to pP64 (R $\alpha \mathrm{P} 64)$ recognized a 60 to $64 \mathrm{kDa}$ band in both sonicate and the P64 preparation; no reactivity was observed with normal rabbit serum. However, this band was occasionally observed to resolve into two distinct bands of $60 \mathrm{kDa}$ and $64 \mathrm{kDa}$ (Fig. 2); some bands of $120 \mathrm{kDa}$ were also observed in P64, which were not seen in serovar hardjo sonicate. Boiling of samples and the presence or absence of dithiothreitol prior to SDS-PAGE had no effect on this banding profile. In an attempt to further resolve the doublet profile of P60-64, serovar hardjo sonicate was subjected to two-dimensional electrophoresis followed by Western blotting with $\mathrm{R} \alpha \mathrm{P} 64$. P60-64 migrated as a single spot in the $\mathrm{pH}$ region of 5 to 7 (not illustrated).

Because $\mathrm{R} \alpha \mathrm{P} 64$ was prepared using SDS-PAGEpurified (denatured) protein it was tested against nondenatured serovar hardjo sonicate and P64 using a native gel system. Serovar hardjo sonicate and P64 were electrophoretically separated on 5,7 and $10 \%$ polyacrylamide gels in the absence of SDS and dithiothreitol; gels were Coomassie-blue-stained for protein or transblotted and immunostained with R $\alpha \mathrm{P} 64$ (Fig. 3). In all cases only one protein of $>670 \mathrm{kDa}$ was observed in the P64 preparation by Coomassie blue staining. $\mathrm{R} \alpha \mathrm{P} 64$, as well as human antisera (not illustrated), reacted with this band in both sonicate and P64 by Western blotting,
Table 2. Cross-reactivity of RaP64 with sonicates of various bacterial species

\begin{tabular}{lc}
\hline \hline Bacterial species & $\begin{array}{c}\text { Reactivity } \\
\text { with R } \alpha \mathrm{P} 64\end{array}$ \\
\hline Leptonema illini & + \\
Treponema pallidum & + \\
Borrelia burgdorferi & + \\
Clostridium perfringens & + \\
Pseudomonas aeruginosa & + \\
Escherichia coli & + \\
Shigella flexneri & + \\
Neisseria gonorrhoeae & $+{ }^{*}$ \\
Neisseria pharyngis & + \\
Proteus mirabilis & $+{ }^{*}$ \\
Campylobacter jejuni & - \\
Bacteroides fragilis & - \\
Streptococcus pyogenes & + \\
Corynebacterium murium & + \\
Pasteurella multocida & + \\
Staphylococcus epidermidis & + \\
Mycobacterium bovis (BCG) & + \\
Bacillus subtilis & - \\
\hline \hline
\end{tabular}

* Reactivity of $\mathrm{R} \alpha \mathrm{P} 64$ with a protein of $42 \mathrm{kDa}$.

indicating that P64 exists as a homomultimeric protein in the native state.

$\mathrm{R} \alpha \mathrm{P} 64$ did not agglutinate homologous leptospires nor did it opsonize them for phagocytosis by murine macrophages as determined by indirect immunofluorescence.

\section{Examination of cross-reactivity of R $\alpha \mathrm{P64}$}

The cross-reactivity of $\mathrm{R} \alpha \mathrm{P} 64$ with representative serovars from serogroups of $L$. interrogans (Table 1 ) was examined by Western blotting. Immunoblots showed identical profiles to those obtained with serovar hardjo (not illustrated). However, R $\alpha$ P64 also reacted with a $60 \mathrm{kDa}$ band in sonicate from serovar patoc (Fig. 4), a member of the saprophytic species L. biflexa; this reactivity was considerably weaker than that obtained with serovar hardjo and the other L. interrogans serovars. The cross-reactivity of R $\alpha \mathrm{P} 64$ against other spirochaetes and various Gram-negative and Gram-positive organisms was further investigated (Table 2); some of these are illustrated in Fig. 4. R $\alpha \mathrm{P} 64$ reacted with a component in these and other bacteria in the 60-67 kDa region, with the exception of Neisseria gonorrhoeae, Proteus mirabilis and Corynebacterium murium where the cross-reactivity was directed against a $42 \mathrm{kDa}$ component. In addition, human sera from a syphilis patient reacted with P64, as did rabbit anti-Borrelia burgdorferi antiserum. Both of 


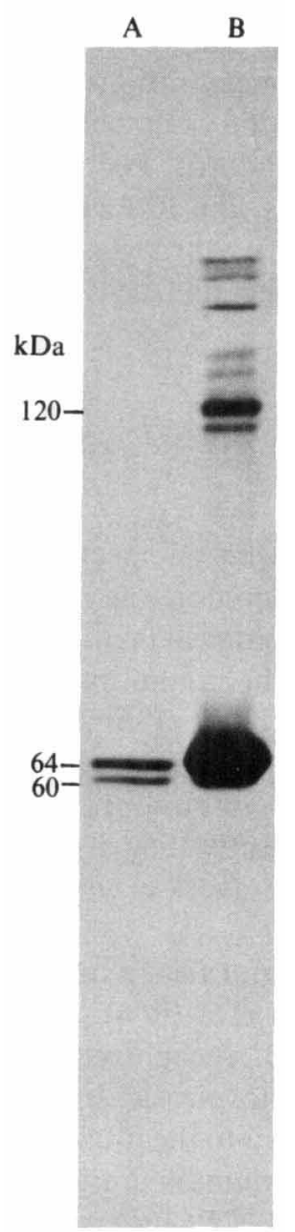

Fig. 2. Serovar hardjo sonicate (A) and P64 (B) separated by SDSPAGE and immunoblotted with $\mathrm{R} \alpha \mathrm{P} 64$ antiserum.

these sera reacted with P64 in an identical manner to $\mathrm{R} \alpha \mathrm{P} 64$ and no cross-reactivity was observed with normal rabbit serum or normal human serum in the regions of interest.

P64 was electrophoresed on a $7 \%(w / v)$ SDSpolacrylamide gel, transblotted onto nitrocellulose and immunostained with $\mathrm{R} \alpha \mathrm{P} 64$ antibodies that had been eluted from the $62 \mathrm{kDa}$ band of Pseudomonas aeruginosa. These eluted antibodies reacted exclusively with the $64 \mathrm{kDa}$ band of P64. In the reverse experiment, R $\alpha \mathrm{P} 64$ antibodies eluted from the $64 \mathrm{kDa}$ band of serovar hardjo sonicate reacted exclusively with the $62 \mathrm{kDa}$ band of $P$. aeruginosa sonicate.

\section{Localization of P64 in the leptospire}

In order to localize P60-64, leptospires were separated into total membrane and cytoplasmic fractions by

Fig. 4. Immunoblotting of sonicates of bacterial species with $\mathrm{R} \alpha \mathrm{P} 64$ Lanes: A, serovar hardjo; B, Leptospira biflexa serovar patoc; C, Leptonema illini; D, Clostridium perfringens; E, Pseudomonas aeruginosa; F, Escherichia coli.

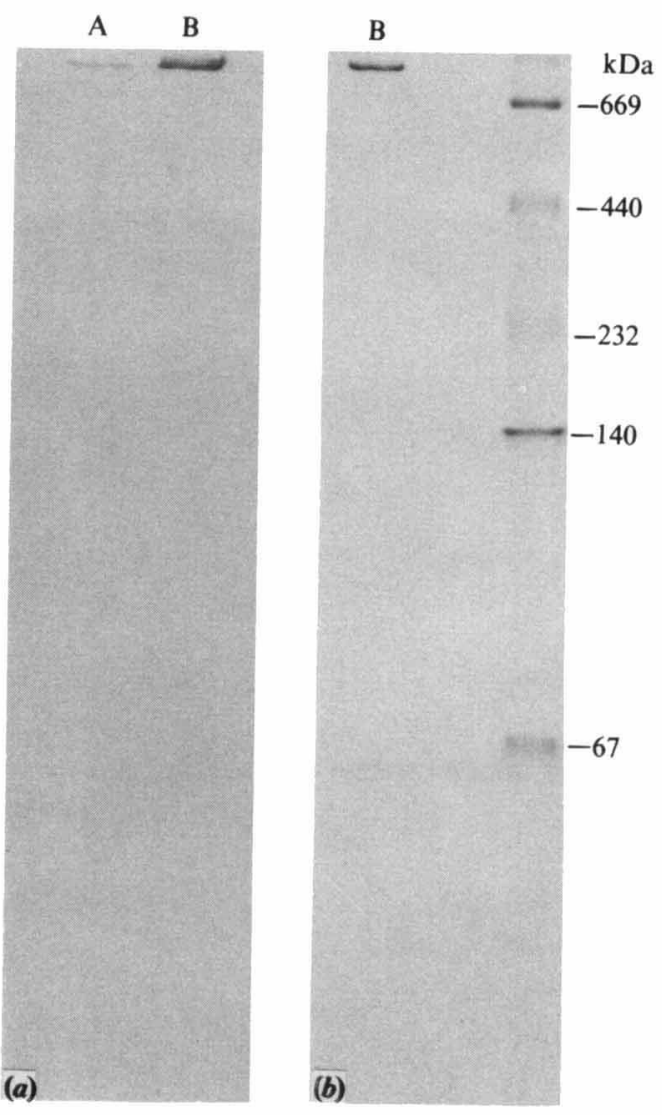

Fig. 3. Native PAGE of serovar hardjo sonicate (A) and P64 (B) on a $7 \%$ polyacrylamide gel, immunoblotted with $\mathrm{R} \alpha \mathrm{P} 64(a)$ or stained with Coomassie blue $(b)$. The right-hand lane in $(b)$ contains standard proteins.

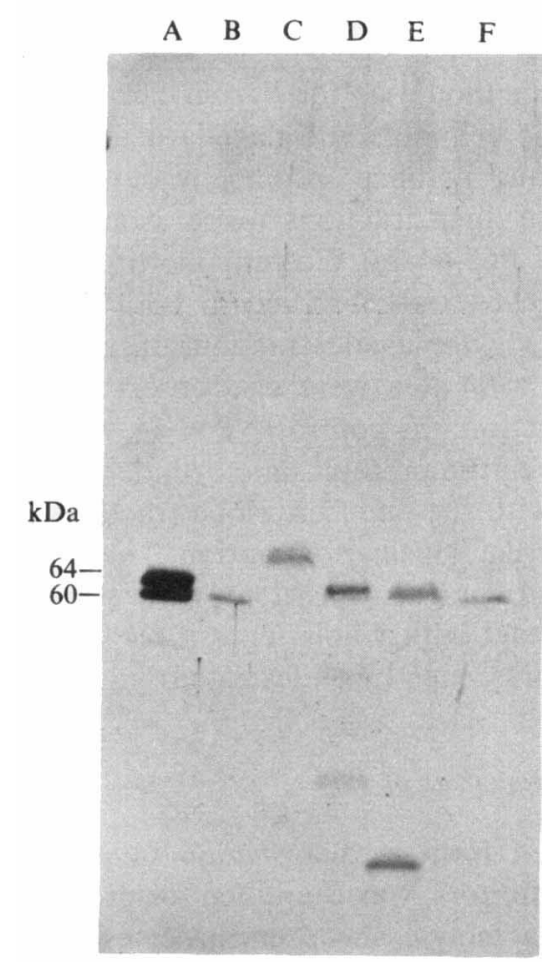




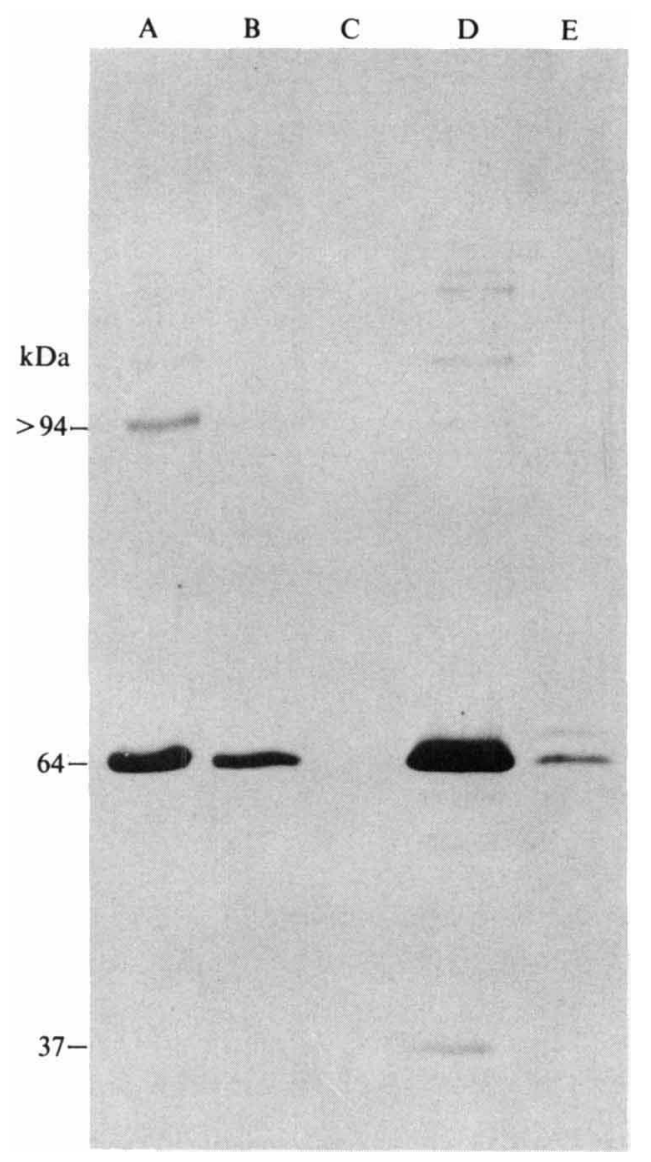

Fig. 5. Localization of P64 by cell fractionation. Evaluation using SDS-PAGE and immunoblotting with R $\alpha$ P64. Lanes: A, cytoplasmic fraction; B, membrane fraction; C, leptospiral flagella; D, protoplasmic cylinders; $\mathrm{E}$, outer envelope.

adapting a method used for $E$. coli. The outer envelope, protoplasmic cylinders and flagella of leptospires were purified using methods specifically devised for Leptospira. These five fractions were examined for the presence of P60-64 by Western blotting using R $\alpha$ P64 (Fig. 5). P60-64 was observed in both the membrane fraction and cytoplasmic fractions in equal amounts; proteins of $>94 \mathrm{kDa}$ were also observed in the cytoplasmic fraction. In contrast, P60-64 was found predominantly in the protoplasmic cylinders of leptospires compared with the outer envelope fraction. $\mathrm{R} \alpha \mathrm{P} 64$ did not react with a flagella preparation. This apparent subsurface location was consistent with the inability of $\mathrm{R} \alpha \mathrm{P} 64$ to react with whole leptospires when tested by immunofluorescence (not illustrated).

\section{Biological properties of P64}

P64, purified from serovar hardjo in the absence of protease inhibitors, was examined for protease activity, ability to haemolyse sheep erythrocytes and cytotoxic effects on a fibroblastic cell line. P64 had no detectable protease activity at concentrations of up to $100 \mu \mathrm{g} \mathrm{ml}^{-1}$ when tested using Azocoll as the substrate and compared with proteinase $\mathrm{K}$ standards. P64 also failed to haemolyse sheep erythrocytes, and $\mathrm{R} \alpha \mathrm{P} 64$ could not inhibit the haemolysis of sheep erythrocytes by serovar hardjo. Finally, P64 had no effect on L cells as measured by LDH leakage.

\section{Discussion}

Antigens shared by a broad spectrum of micro-organisms, referred to as common antigen(s), display similar structural and immunological features. In particular they can be isolated as homomultimers of $250-900 \mathrm{kDa}$ comprising $60 \mathrm{kDa}$ subunits (Shinnick et al., 1988) and all contain species-specific and genus-specific epitopes as well as cross-reactive epitopes (Gillis et al., 1985). Perhaps more importantly they are major immunogens and antigens during infection with the corresponding bacteria.

In this study, we purified a major protein with a molecular mass of $64 \mathrm{kDa}$ (P64) from Leptospira interrogans serovar hardjo, recognized by humans during naturally acquired leptospirosis. Immunological characterization of P64 has led to the preliminary identification of this protein as the common antigen of Leptospira. The native molecular mass of P64 was calculated, using nondenaturing PAGE, to be greater than $670 \mathrm{kDa}$ occurring as a homomultimeric protein composed of $64 \mathrm{kDa}$ subunits. When tested by Western blotting, P64 reacted with human antiserum, rabbit antiserum produced against other spirochaetes, namely $B$. burgdorferi and $T$. pallidum, as well as with monospecific rabbit antiserum raised against P64 ( $\alpha$ P64). To investigate this immunological cross-reactivity further, $\mathrm{R} \alpha \mathrm{P} 64$ was used to screen a variety of other micro-organisms as well as representative serovars from the genus Leptospira. On immunoblots, this antiserum reacted with a $64 \mathrm{kDa}$ band in all leptospiral serovars tested (Table 1) as well as with a 60 $64 \mathrm{kDa}$ region in 12 out of $18 \mathrm{Gram}$-negative and Grampositive organisms tested; three organisms exhibited a cross-reactive protein of $42 \mathrm{kDa}$ and the remaining three organisms gave no reaction (Table 2). The common antigen of $P$. aeruginosa consists of $62 \mathrm{kDa}$ subunits (Sompolinsky et al., 1980) and it is to this standard that the findings for other bacteria have been compared, the subunit molecular mass of common antigens falling in the narrow range of 59 to $65 \mathrm{kDa}$. However the Tr-c antigen of $T$. phagedenis has been characterized as a homomultimeric protein composed of $48 \mathrm{kDa}$ subunits which cross-reacts immunologically with the common antigen of $P$. aeruginosa (Hindersson et al., 1984). 
The level of cross-reactivity of $\mathrm{R} \alpha \mathrm{P} 64$ outside the genus Leptospira was considerably weaker than that within the genus, indicating the probable existence of at least genus-specific epitopes, as well as cross-reactive epitopes. To confirm the existence of cross-reactive epitopes, R $\alpha \mathrm{P} 64$ was reacted with serovar hardjo, and P64-specific antibodies were eluted from the $64 \mathrm{kDa}$ band and tested against $P$. aeruginosa by Western blotting. In the reverse experiment, antibodies were eluted from the cross-reactive $62 \mathrm{kDa}$ protein in $P$. aeruginosa immunoblots and tested against P64. In both cases eluted antibodies reacted exclusively with the homologous protein, confirming that the cross-reactivity observed with R $\alpha$ P64 serum was a function of anti-P64 antibodies and not due to non-specific cross-reactivity of the rabbit antisera used.

The reactivity of $\mathrm{R} \alpha \mathrm{P} 64$ with the purified protein and serovar hardjo sonicate occasionally manifested as a doublet, leading to initial concerns that this antiserum was not monospecific. Bands observed with a molecular mass of $120 \mathrm{kDa}$ could be explained as dimers of P64 resulting from incomplete degradation of the homomultimeric form. Two-dimensional electrophoresis was done in an attempt to resolve this doublet profile further; however when immunoblotted with $\mathrm{R} \alpha \mathrm{P} 64$ only one reactive spot was observed which had a slightly acidic isoelectric point characteristic of other common antigens (Sompolinsky et al., 1980). The common antigen in other bacteria was also partially degraded to low-molecularmass products or observed as doublets (Gillis et al., 1985; Thole et al., 1988; Shinnick et al., 1988). The source of this doublet profile is unknown and could be the result of enzymic cleavage or degradation of the P64 subunit. Alternatively, these proteins may result from a normal precursor/product relationship such as that observed with proteins requiring signal peptides to traverse the bacterial membrane.

Initial attempts to localize P64 in the leptospire, using immunogold-labelling of ultra-thin sections of whole leptospires, were unsuccessful. However, in cell fractionation experiments, P64 appears to have a sub-surface location, occurring predominantly in the cytoplasm with some membrane involvement. Whilst P64 was found in the outer envelope of the leptospire, it is unlikely that it is surface-exposed as intact leptospires did not react with $\mathrm{R} \propto \mathrm{P} 64$ when tested by immunofluorescence. Gillis $e t$ al. (1985) found that the common antigen of Mycobacterium leprae was associated with the cell wall, whereas Thole $e t$ al. (1988) showed a cytoplasmic location for the common antigen of Mycobacterium bovis using immunogoldlabelling. In other studies, the common antigen of $B$. burgdorferi and $P$. aeruginosa had a sub-surface location (Hansen et al., 1988).

Humans produce antibodies to P64 during naturally acquired leptospirosis but it is unlikely that $\mathbf{P} 64$ plays a role in immunity to infection as it does not give rise to agglutinating antibodies, nor did R $\propto \mathrm{P} 64$ antibodies opsonize whole leptospires for phagocytosis by murine macrophages. This is not surprising considering the apparent sub-surface location of P64.

The common antigen of $M$. bovis has been implicated in the pathogenesis of experimental adjuvant arthritis. Using $T$ cell clones, capable of inducing arthritis in rats, along with truncated peptides of cloned $M$. bovis common antigen, the arthritogenic eptitope was localized (Van Eden et al., 1988). The presence of this or a cross-reactive epitope in the common antigen of different bacteria, including Leptospira, remains to be elucidated, but may explain why only some of the many bacteria expressing common antigen are associated with arthritis. Although the role of $T$ cell immunity during infection with Leptospira is unclear, the fact that arthritis is not a common clinical feature of leptospirosis seems to indicate that the leptospiral common antigen may differ from that of $M$. bovis in this aspect. In an attempt to identify a cytotoxic function for P64 the purified protein was tested for protease activity, ability to haemolyse sheep erythrocytes and L cell cytotoxicity. P64 was inactive in all experiments. Although the possibility of some cytotoxic function is not precluded it seems unlikely that P64 would play such a role in the pathogenesis of leptospirosis.

The phylogenetic stability of common antigen is remarkable and suggests a vital but elusive physiological function. Recently the common antigen of $M$. tuberculosis has been identified as a heat-shock protein produced in response to environmental stress (Young et al., 1988). Subsequently, the common antigen of Coxiella burnetii has been implicated in the heat-shock response of this organism (Vodkin \& Williams, 1988). Both of these common antigens corresponded to a similar antigen in $E$. coli (the GroEL protein) which is also expressed as a heat-shock protein. The mechanism of virulence in Leptospira is obscure, but it has been shown that virulent leptospires survive and multiply in host tissues, whereas avirulent leptospires do not (Faine, 1957). Faine (1959) showed that avirulent strains were susceptible to physiological concentrations of $\mathrm{NaCl}$ at $37^{\circ} \mathrm{C}$ but not at $30^{\circ} \mathrm{C}$, whereas virulent leptospires grew normally. In addition, virulent strains grew in rabbit serum medium at $40^{\circ} \mathrm{C}$ and avirulent strains did not. It is interesting to speculate whether or not P64 may play a role in the survival of leptospires during heat stress in a similar manner to the heat-shock protein/common antigen of other bacteria. This and other studies will be the subject of further investigation.

Addendum. Two mouse monoclonal antibodies, 
mc5205 and mc0445, against the $65 \mathrm{kDa}$ common antigen/heat-shock protein of Mycobacteria, were obtained from the UNPD/World Bank/WHO Special Programme for Research and Training in Tropical Diseases [Engers et al. (1985). Letter. Infection and Immunity 48, 603-605]. These antibodies were tested for reactivity against P64 and serovar hardjo sonicate by Western blotting. Both antibodies reacted with a single band of $64 \mathrm{kDa}$ in these antigen preparations, confirming the identification of P64 as the common antigen of Leptospira.

This work was supported by a grant from the National Health and Medical Research Council, Canberra, Australia.

\section{References}

AdLER, B. \& FAINE, S. (1978). The antibodies involved in the human immune response to leptospiral infection. Infection and Immunity 11, $387-400$.

ADLER, B. \& FAINE, S. (1983). A pomona serogroup-specific, agglutinating antigen in Leptospira, identified by monoclonal antibodies. Pathology 15, 247-250.

Adler, B., Murphy, A. M., Locarnini, S. A. \& Faine, S. (1980). Detection of specific anti-leptospiral immunoglobulins $M$ and $G$ in human serum by solid-phase enzyme-linked immunosorbent assay. Journal of Clinical Microbiology 11, 452-457.

AURAN, N. E., Johnson, R. C. \& Ritzi, D. M. (1972). Isolation of the outer sheath of Leptospira and its immunogenic properties in hamsters. Infection and Immunity 5, 968-975.

BeALl, J. A. \& Mitchell, G. F. (1986). Identification of a particular antigen from a parasite cDNA library using antibodies affinity purified from portions of Western blots. Journal of Immunological Methods 86, 217-223.

Boulard, C. \& LeCRoISEy, A. (1982). Specific antisera produced by direct immunization with slices of polyacrylamide gel containing small amounts of protein. Journal of Immunological Methods 50, 221-226.

BRADFORD, M. M. (1976). A rapid and sensitive method for the quantitation of microgram quantities of protein utilizing the principle of protein-dye binding. Analytical Biochemistry $\mathbf{7 2}$, $248-254$.

Chang, A. \& FaINe, S. (1970). Electron microscopic evidence for reactions of axial filaments of Leptospira with IgM and IgG antibodies. Bulletin of the World Health Organization 43, 571-577.

Chapman, A. J., AdLeR, B. \& FaINE, S. (1987). Genus-specific antigens in Leptospira revealed by immunoblotting. Zentralblatt für Bakteriologie, Mikrobiologie und Hygiene 264, 279-293.

Chapman, A. J., Adler, B. \& Faine, S. (1988). Antigens recognised by the human immune response to infection with Leptospira interrogans serovar hardjo. Journal of Medical Microbiology 25, 269-278.

FAINE, S. (1957). Virulence in Leptospira. II. The growth in vivo of virulent Leptospira icterohaemorrhagiae. British Journal of Experimental Pathology 38, 8-14.

FAINE, S. (1959). Virulence in Leptospirae. III. Comparison of sensitivities of virulent and of avirulent Leptospira icterohaemorrhagiae to cultural conditions. Journal of Bacteriology 77, 599-603.

Farrelly, H. E., AdLer, B. \& FaINe, S. (1987). Opsonic monoclonal antibodies against lipolysaccharide antigens of Leptospira interrogans serovar hardjo. Journal of Medical Microbiology 23, 1-7.

Gillis, T. P., Miller, R. A., Young, D. B., Khanolkar, S. R. \& Buchanan, T. M. (1985). Immunochemical characterization of a protein associated with Mycobacterium leprae cell wall. Infection and Immunity 49, 371-377.
Hansen, K., Bangsborg, J. M., Fuordvang, H., Pedersen, N. S. \& HiNDERSSON, P. (1988). Immunochemical characterization of and isolation of the gene for a Borrelia burgdorferi immunodominant 60kilodalton antigen common to a wide range of bacteria. Infection and Immunity 56, 2047-2053.

HaWkes, R., Niday, E. \& Gordon, J. (1982). A dot-immunobinding assay for monoclonal and other antibodies. Analytical Biochemistry 119, $142-147$.

Hindersson, P., Petersen, C. S., Pederson, N. S., Hoiby, N. \& AXELSEN, N. H. (1984). Immunological cross-reaction between antigen Tp-4 of Treponema pallidum and an antigen common to a wide range of bacteria. Acta Pathologica et Microbiologica Scandinavica B92, 183-188.

HoIBY, N. (1975). Cross-reactions between Pseudomonas aeruginosa and thirty six other bacterial species. Scandinavian Journal of Immunology (suppl.) 2, 187-196.

Ito, K., Sato, T. \& YURA, T. (1977). Synthesis and assembly of the membrane proteins in E. coli. Cell 11, 551-559.

JACOBS, E. \& CLAD, A. (1986). Electro-elution of fixed and stained membrane proteins from preparative SDS-polyacrylamide gels into a membrane trap. Analytical Biochemistry 154, 583-589.

Johnson, R. C., Walby, J., Henry, R. A. \& Auran, N. E. (1973). Cultivation of parasitic leptospires: effect of pyruvate. Applied Microbiology 26, 118-119.

JosT, B. H., AdLER, B., VINH, T. \& FaINE, S. (1986). A monoclonal antibody reacting with a determinant on leptospiral lipopolysaccharide protects guinea pigs against leptospirosis. Journal of Medical Microbiology 22, 269-275.

JosT, B. H., ADLER, B. \& FAINE, S. (1988). Reaction of monoclonal antibodies with species specific determinants in Leptospira interrogans outer envelope. Journal of Medical Microbiology 27, 51-57.

Jost, B. H., ADLER, B. \& FAINE, S. (1989). Experimental immunisation of hamsters with lipopolysaccharide antigens of Leptospira interrogans. Journal of Medical Microbiology 29, 115-120.

KAIJSER, B. (1975). Immunological studies of an antigen common to many Gram-negative bacteria with special reference to $E$. coli. International Archives of Allergy $48,72-81$.

Kelson, J. S., Adler, B., Chapman, A. J. \& Faine, S. (1988). Identification of leptospiral flagellar antigens by gel electrophoresis and immunoblotting. Journal of Medical Microbiology 26, 47-53.

MCGrath, H., AdLeR, B., Vinh, T. \& Faine, S. (1984). Phagocytosis of virulent and avirulent leptospires by guinea-pig and human polymorphonuclear leukocytes in vitro. Pathology 16, 243-249.

Milner, A. R., Beall, J. A. \& ORWAT, A. (1987). Two-dimensional electrophoretic comparison of the antigens and biosynthetically labelled proteins of Trichostrongylus colubriformis and Ostertagia circumcincta. Parasite Immunology 9, 615-626.

Mitchell, D. B., SANTone, K. S. \& Acosta, D. (1980). Evaluation of cytotoxicity in cultured cells by enzyme leakage. Journal of Tissue Culture Methods 6, 113-116.

MORRISSEY, J. H. (1981). Silver stain for proteins in polyacrylamide gels: a modified procedure with enhanced uniform sensitivity. Analytical Biochemistry 117, 307-310.

Nunes-Edwards, P. L., ThIERManN, A. B., Bassford, P. J. \& STAMm, L. V. (1985). Identification and characterization of the protein antigens of Leptospira interrogans serovar hardjo. Infection and Immunity 48, 492-497.

Radolf, J. D., Chamberlain, N. R., Clausell, A. \& Norgard, M. (1988). Identification and localization of integral membrane proteins of virulent Treponema pallidum subsp. pallidum by phase partitioning with the nonionic detergent Triton X-114. Infection and Immunity 56, 490-498.

Sakamoto, N., Ono, E., Kida, H. \& Yanagawa, R. (1985a). Production of monoclonal antibodies against leptospiral genusspecific protein antigen and localization of the antigen by immunoelectron microscopy. Zentralblatt für Bakteriologie, Mikrobiologie und Hygiene Series A 259, 557-563.

Sakamoto, N., Yanagawa, R., Ono, E., Kida, H., Mori, M., ARImitsu, Y., AKama, K., Yasuda, J. \& Too, K. (1985b). Detection of antibodies to leptospiral genus-specific antigen in human and animal sera by indirect hemagglutination test with a partially purified genus-specific protein antigen. Zentralblatt für Bakteriologie, Mikrobiologie und Hygiene Series A 259, 548-556. 
Shinnick, T. M., Vodkin, M. H. \& Williams, J. C. (1988). The Mycobacterium tuberculosis 65-kilodalton antigen is a heat shock protein which corresponds to common antigen and to the Escherichia coli GroEL protein. Infection and Immunity 56, 446-451.

Sompolinsky, D., Hertz, J. B., Hoiby, N., Jensen, K. MANSA, B. Pedersen, V. B. \& Samra, Z. (1980). An antigen common to a wide range of bacteria. 2. A biochemical study of a 'common antigen' from Pseudomonas aeruginosa. Acta Pathologica et Microbiologica Scandinavica B88, 253-260.

Thole, J. E. R., Hindersson, P., de Bruyn, J., Cremers, F., van der Zee, J., de Cock, H., Tommassen, J., Van Eden, W, \& VaN EMBDEN, J. D. A. (1988). Antigenic relatedness of a strongly immunogenic $65 \mathrm{kDa}$ mycobacterial protein antigen with a similarly sized ubiquitous bacterial common antigen. Microbial Pathogenesis 4, 71-83.

VAN Eden, W., Thole, J. E. R., VAN Der Zee, R., NoordziJ, A., VaN Embden, J. D. A., Hensen, E. J. \& CoHEN, I. (1988). Cloning of the mycobacterial epitope recognized by T-lymphocytes in adjuvant arthritis. Nature, London 331, 171-173.
VINH, T., ADLER, B. \& FAINE, S. (1982). The role of macrophages in the protection of mice against leptospirosis: in vitro and in vivo studies. Pathology 14, 463-468.

VINH, T., FAINE, S. \& ADLER, B. (1984). Adhesion of leptospires to mouse fibroblasts (L929) and its enhancement by specific antibody. Journal of Medical Microbiology 18, 73-85.

VINH, T., ADLER, B. \& FAINE, S. (1986). Glycolipoprotein cytotoxin from Leptospira interrogans serovar copenhageni. Journal of General Microbiology 132, 111-123.

Vodkin, M. H. \& Williams, J. C. (1988). A heat shock operon in Coxiella burnetii produces a major antigen homologous to a protein in both Mycobacteria and Escherichia coli. Journal of Bacteriology 170 , 1227-1234.

Young, D. B., Lathigra, R., Hendrix, R., Sweetser, D. \& Young, R. A. (1988). Stress proteins are immune targets in leprosy and tuberculosis. Proceedings of the National Academy of Sciences of the United States of America 85, 4267-4270. 